\title{
Comparison of minimally invasive video-assisted thyroidectomy and conventional thyroidectomy: a single-blinded, randomized controlled clinical trial
}

This article was published in the following Dove Press journal:

Open Access Surgery

24 March 2010

Number of times this article has been viewed

\author{
Gouda Mohamed El-labban \\ Department of General Surgery, \\ Faculty of Medicine, Suez Canal \\ University, Ismailia, Egypt
}

Aim: We aimed to test the hypothesis that minimally invasive video-assisted thyroidectomy (MIVAT) affords comparable safety and efficacy as open conventional surgery in patients with unilateral thyroid nodules or follicular lesions in terms of cosmetic results, intraoperative and postoperative complications, postoperative pain, and hospital stay.

Methods: A single-blinded randomized controlled trial compared MIVAT with conventional thyroidectomy. The primary endpoints of the study were measurement of postoperative pain after 24 and 48 hours and cosmetic outcome 3 months postoperatively. The secondary outcome measures were operative time, incidence of recurrent laryngeal nerve injury, length of incision, and hospital stay.

Results: Operative time was less with open thyroidectomy than with MIVAT, while MIVAT was associated with less pain 24 hours postoperatively. Pain score showed statistically significant differences in favor of MIVAT after 24 hours. MIVAT was associated with less scarring and more satisfaction with cosmetic results. There was no difference between both procedures for presence of transient recurrent laryngeal nerve palsy and hypoparathyroidism.

Conclusion: MIVAT is a safe procedure that produces outcomes similar to those of open thyroidectomy, and is superior in terms of immediate postoperative pain and cosmetic results

Keywords: endoscopic neck surgery, mini-incision

\section{Introduction}

Neck surgery is one of the newest and most interesting applications of minimally invasive surgery. Many reports on the use of this technique in thyroid surgery, particularly for eliminating the unattractive scars sometimes caused by conventional surgery, have been published. ${ }^{1-11}$ Minimal-access thyroid surgery was conceived primarily in Europe and Asia. A number of groups ${ }^{11-17}$ have made pioneering contributions to this field. While a variety of minimally invasive approaches have been endorsed, the technique most widely practiced in North America is minimally invasive video-assisted thyroidectomy (MIVAT), as originally described by Miccoli et al. ${ }^{12}$ As with many new surgical techniques, adoption of MIVAT in the United States has been slow and somewhat deliberate. Increasingly, however, high-volume thyroid surgical centers have embraced this approach, and modest-sized case series have been published detailing their experiences. ${ }^{18,19}$ In a more comprehensive reflection of the North American experience with MIVAT, consolidated data were compiled prospectively at 4 academic medical centers, paying specific attention to the safety and feasibility of this approach. ${ }^{20}$. Several surgeons reported their experiences with minimally invasive and video-assisted surgery of the neck. ${ }^{2,12,13,21-40}$ Although all these evidence-based studies reported short- and long-term
Correspondence: Gouda Mohamed El-labban Department of General Surgery, Faculty of Medicine, Suez Canal University, Round Road, Ismailia, Egypt $\mathrm{Tel}+20$ I0 3530I0I (Cell);+20 643381302 (Bus); +20 463211612 (Home) Fax +20643208543

Email ellabbang@yahoo.com 
outcomes, and data after endoscopic resections for different thyroid diseases showed clear advantages in comparison with traditional procedures, mini-invasive thyroid surgery has not been accepted. ${ }^{13,19,41-46}$ One of the reasons for this initial refusal is partly due to the technical difficulty of endoscopic resection, which requires adequate training both in open and endoscopic procedures before gland resection can be safely performed. ${ }^{46}$

MIVAT has the potential to offer similar advantages over conventional thyroidectomy. However, almost a decade after the early descriptions of endoscopic thyroidectomy, MIVAT remains in an early phase of its evolution, with a variety of techniques practiced in a relatively small number of specialist centers internationally. ${ }^{47}$ While the feasibility of MIVAT approaches has been well documented, few studies have observed these techniques in the setting of a randomized trial. The minimally invasive approaches have demonstrated some advantages in terms of cosmetic and pain outcomes. ${ }^{13,42}$ While this approach appears anecdotally to have benefits over conventional thyroidectomy, a randomized clinical trial is needed to avoid the selection bias inherent in retrospective studies and surgical case series. ${ }^{48}$

We aimed to compare the outcomes of MIVAT with conventional surgery in patients presenting with unilateral thyroid nodules or follicular lesions.

\section{Patients and methods}

\section{Study design}

A single-blinded, randomized clinical trial comparing MIVAT with conventional hemithyroidectomy was undertaken in the Suez Canal University Hospital from January 2002 to December 2007. The trial was approved by the Faculty of Medicine, Suez Canal University Research Ethics Committee, and written informed consent was obtained from all participants prior to entry into the trial. The study population included those patients with unilateral, thyroid nodules or follicular lesions requiring hemithyroidectomy for further histological diagnosis. Patients with small solitary toxic thyroid nodules were also eligible for participation. Patients were considered for randomization if they had unilateral nodular disease with a maximum nodule diameter of $\leq 3.0 \mathrm{~cm}$ and were able to give informed consent. Participants were considered ineligible if preoperative fine needle cytology showed thyroid carcinoma, nodule diameter was $>3.0 \mathrm{~cm}$, active thyroiditis was evident, or there was a history of previous neck surgery or head and neck irradiation.

\section{Operative technique}

Patients were randomized to undergo diagnostic hemithyroidectomy by either MIVAT or conventional method. All patients were blinded to the allocated procedure preoperatively. The procedure was performed by the same surgeon, who was aware of the procedure type at the time of randomization. All patients underwent preoperative fiberoptic laryngoscopy to assess vocal cord movement. Both procedures were performed by a standardized technique. All patients had local infiltration of subcutaneous tissues beneath the incision with $5 \mathrm{~mL}$ of bupivacaine $0.5 \%$ with adrenaline.

The technique for MIVAT has been described previously by Miccoli et al. ${ }^{13}$ Gasless video-assisted thyroid surgery was used. The patients were operated on under general endotracheal anesthesia. The patient was placed in the supine position and the neck was not hyperextended. Depending on the nodule size, a $2-\mathrm{cm}$ or $2.5-\mathrm{cm}$ horizontal skin incision was made $2 \mathrm{~cm}$ above the clavicle. An upper flap was created by subplatysmal dissection and elevated to create a tent-like working space, which provided a comfortable space for simultaneous insertion of a $3.3-\mathrm{mm} 0^{\circ}$ laparoscope and instruments through the same skin incision. With endoscopic assistance, subplastysmal dissection was carefully performed to avoid bleeding. The cervical linea alba was divided longitudinally as far up as the thyroid cartilage. The overlying strap muscles were dissected off the thyroid. The strap muscles on the affected side were retracted using an Army-Navy retractor to expose the thyroid and hold open the dissection space. An Fr 10 suction catheter was attached to the scope for continuous suction of warm air in the wound to prevent blurry scope optics. The middle thyroid vein or the small veins between the jugular vein and thyroid were divided with a harmonic scalpel. An Allis tissue forceps was applied to the upper portion of the thyroid, allowing a downward and lateral traction of the thyroid. The avascular space between the upper pole of the thyroid and the cricothyroid muscle was opened to identify the external branch of the superior laryngeal nerve. The superior thyroid vessels were selectively isolated and divided using a harmonic scalpel. After dividing the superior thyroid vessels, the upper portion of the thyroid was gently extracted from the incision using an Allis forceps. Gentle traction over the thyroid enabled the gland to be extracted without rupture. Then the inferior thyroid artery was exposed, and the parathyroid glands and recurrent laryngeal nerve were identified clearly. The inferior thyroid artery was ligated and not divided on the thyroid capsule distal to its supply of the parathyroid glands. The thyroid was freed from the trachea by ligating the small vessels and dissecting the ligament of Berry. The isthmus was then dissected from the trachea and divided by the harmonic scalpel. The specimen excised was extracted from the wound and a small suction drain was left inside. The wound was closed with absorbable sutures. 
Conventional hemithyroidectomy was performed as described by Lennquist ${ }^{49}$ using a 5- to 6-cm Kocher incision and division of the ipsilateral strap muscles. After this exposure, the operative technique then mirrored that used in the MIVAT approach. A standard dressing was applied for both MIVAT and conventional cases, with adhesive surgical tape placed horizontally across the neck. Patients were observed in the 24-hour ward and discharge was planned for the morning of the following day.

\section{Outcome measures}

The primary endpoints of the study were measurement of postoperative pain 24 and 48 hours after the operation and self-rated patient satisfaction, with cosmetic outcome 3 months postoperatively. Postoperative pain scores were measured using a 10-point visual analog scale (VAS) postoperatively. The patients were asked to assess the severity of pain by the means of VAS, which usually consists of a $10-\mathrm{cm}$ line with the words "no pain" on the left hand side and "the worst pain imaginable" on the other side. The patients were asked to evaluate their pain 6, 24, 48 hours after the operation by indicating a pain level on the VAS (score 0 for no pain, VAS $1-2$ is excellent, VAS $3-5$ is good, VAS $>5$ is poor). ${ }^{50}$ A higher numeric pain score represented more severe pain. Satisfaction with cosmetic outcome was measured at the follow-up using a 10-point VAS..$^{51}$

The secondary outcome measures were operative time, incidence of temporary and permanent recurrent laryngeal nerve injury, postoperative hematoma formation, length of incision, and duration of hospital stay.

The operative time was measured to the nearest minute from initiation of the incision to subcuticular closure. Recurrent laryngeal nerve function was assessed blindly preoperative and at 2 to 4 weeks after the operation and then repeated a month later, if there was any evidence of nerve injury. Postoperative hematoma was considered significant if it required a return to the operating room for evacuation. At the final 3-month follow-up scars were assessed using the Manchester scar assessment tool, and patients then completed a satisfaction assessment form. ${ }^{51}$

\section{Randomization}

Randomization was performed prior to study commencement as follows: Opaque envelopes were numbered sequentially from 1 to 76. A computer-generated table of random numbers was used for group assignment; if the last digit of the random number was from 0 to 4 , assignment was to Group A (MIVAT), and if the last digit was from 5 to 9, assignment was to Group B (conventional thyroidectomy). The assignments were then placed into the opaque envelopes and the envelopes sealed. As eligible participants were entered into the trial, these envelopes were opened in sequential order to give each patient his or her random group assignment. The envelopes were opened by the operating surgeon after patient consent and just prior to the surgery.

\section{Statistical analysis}

Simple randomization was performed using an automated method without stratification. We determined that a sample size of 76 patients (calculated by the Epu Info ${ }^{\mathrm{TM}}$ program) would give a power of greater than 80 and Beta error 20 to determine a $25 \%$ difference in outcome between the two study groups at a significance level of $P<0.05$. Normally distributed continuous data were assessed using Student's $t$-test. Categorical data were compared using Fisher's exact test. Statistical significance was set at $P<0.05$. Data were analyzed using the SPSS 13 statistical software package.

\section{Results \\ Patient characteristics}

The clinical characteristics of the 76 patients (21 males and 55 females), who were divided into two equal groups, were similar in each group. There was a predominance of females in both groups, and the mean nodule size was equivalent between the groups without any significant difference. The clinical characteristics are summarized in Table 1.

\section{Surgical treatment}

No patients in the MIVAT group required conversion to conventional surgery. The operative time was greater for

Table I Clinical characteristics of both studied groups

\begin{tabular}{|c|c|c|c|}
\hline $\begin{array}{l}\text { Clinical } \\
\text { characteristic }\end{array}$ & $\begin{array}{l}\text { MIVAT group } \\
(n=38)\end{array}$ & $\begin{array}{l}\text { Conventional } \\
\text { group }(n=38)\end{array}$ & $P$ value \\
\hline \multicolumn{4}{|l|}{ Age (years) } \\
\hline Mean \pm SD & $40 \pm 17$ & $42 \pm 19$ & 0.63 \\
\hline \multicolumn{4}{|l|}{ Gender } \\
\hline Male/female (\%) & I I/27 (28.9/7I.I) & $10 / 28(26.3 / 73.7)$ & 0.70 \\
\hline \multicolumn{4}{|l|}{ Site of nodules } \\
\hline Right lobe (\%) & $15(39.5)$ & $18(47.4)$ & 0.36 \\
\hline Left lobe (\%) & $13(34.2)$ & $15(39.5)$ & \\
\hline Isthmus (\%) & $10(26.3)$ & $5(13.1)$ & \\
\hline \multicolumn{4}{|c|}{ Nodule size by ultrasound $(\mathrm{cm})$} \\
\hline Mean \pm SD & $2.7 \pm 0.7$ & $2.9 \pm 0.3$ & 0.11 \\
\hline
\end{tabular}

Abbreviation: MIVAT, minimally invasive video-assisted thyroidectomy. 
the MIVAT cases than conventional cases $(P<0.0001)$. On average, operative time of the MIVATS procedure was 16 minutes longer than that of the conventional procedure. There were no significant differences in estimated intraoperative blood loss or length of hospital stay. Two patients developed temporary recurrent laryngeal nerve paralysis in the MIVAT group and 1 in the conventional group. Only 1 patient had permanent recurrent laryngeal nerve injury in the MIVAT group. No patient required return to the operating room for evacuation of hematoma. The operative details and complication rates are summarized in Table 2.

\section{Outcome measures}

Pain scores as measured on the 10-point VAS were significantly less in the MIVAT group after the first postoperative day than in the conventional group. The mean pain score after day 1 was 2.6 for the MIVAT group and 3.4 for the conventional group. There was no statistically significant difference in pain scores measured 48 hours postoperatively $(P>0.05)$. The mean doses of intramuscular diclofenac sodium given after surgery were significantly lower in the MIVAT group (40 mg) than the conventional group (66 mg) $(P<0.0001)$; $150 \mathrm{mg}$ of diclofenac per day was the maximum dose given.

Table 2 Details of surgical treatment in both studied groups

\begin{tabular}{|c|c|c|c|}
\hline Surgical details & $\begin{array}{l}\text { MIVAT } \\
\text { group }(n=38)\end{array}$ & $\begin{array}{l}\text { Conventional } \\
\text { group }(n=38)\end{array}$ & $P$ value \\
\hline \multicolumn{4}{|c|}{ Duration of procedure (minutes) } \\
\hline Mean \pm SD & $62 \pm 21$ & $46 \pm 5$ & $<0.0001$ \\
\hline \multicolumn{4}{|c|}{ Estimated blood loss (mL) } \\
\hline $\begin{array}{l}\text { Intraoperative } \\
\text { mean } \pm S D\end{array}$ & $39 \pm 13.3$ & $36.0 \pm 19.5$ & 0.44 \\
\hline $\begin{array}{l}\text { Postoperative } \\
\text { mean } \pm S D\end{array}$ & $15 \pm 2.5$ & $14.2 \pm 1.7$ & 0.11 \\
\hline \multicolumn{4}{|c|}{ Duration of hospital stay (days) } \\
\hline Mean \pm SD & $1.2 \pm 0.4$ & $1.04 \pm 0.5$ & 0.13 \\
\hline \multicolumn{4}{|c|}{ Recurrent laryngeal nerve dysfunction } \\
\hline Temporary injury (\%) & $2(5.3)$ & I (2.6) & 0.88 \\
\hline Permanent injury (\%) & I (2.6) & 0 & 0.99 \\
\hline \multicolumn{4}{|l|}{ Hematoma } \\
\hline $\begin{array}{l}\text { Significant require } \\
\text { return to } O R\end{array}$ & 0 & 0 & 1.00 \\
\hline Insignificant & 0 & 0 & 1.00 \\
\hline \multicolumn{4}{|l|}{ Wound infections } \\
\hline No (\%) & $2(5.3)$ & $2(5.3)$ & 1.00 \\
\hline \multicolumn{4}{|l|}{ Hypoparathyroidism } \\
\hline No (\%) & $2(5.3)$ & $2(5.3)$ & 1.00 \\
\hline
\end{tabular}

Abbreviation: MIVAT, minimally invasive video-assisted thyroidectomy.
At 3 months postoperatively, patients in the MIVAT group reported a significantly greater satisfaction with the cosmetic outcome of their procedure than patients in the conventional group. The mean satisfaction rating for the MIVAT group was 9.1 versus 4.9 for the conventional group on a scale of 1 to 10, with 10 representing the best possible outcome. Incision length was significantly smaller in the MIVAT group than the conventional group $(3.2 \pm 0.9$ versus $5.4 \pm 0.7 \mathrm{~cm}$, respectively). The outcome data for pain scores and satisfaction with cosmetic appearance are summarized in Table 3.

\section{Histopathology}

At final histologic assessment, the most common underlying pathology was benign nodular goiter, colloid nodule, or cyst. The next most frequent diagnosis was follicular adenoma. Overall, 3 patients had a malignant diagnosis, all of whom were in the conventional group. The identified malignant conditions were papillary microcarcinoma in association with nodular change, and these patients were later treated by radioactive iodine and follow-up.

\section{Discussion}

This study shows that in patients with small thyroid nodules the minimally invasive approach to thyroidectomy has some advantages over conventional thyroidectomy. The benefits of the MIVAT technique were demonstrated by less pain in the early postoperative period and superior cosmetic results at 3-month follow-up. The MIVAT approach represents a refinement in operative technique for thyroidectomy which is

Table 3 Outcomes after thyroidectomy treatment in both studied groups

\begin{tabular}{|c|c|c|c|}
\hline Outcomes & $\begin{array}{l}\text { MIVAT } \\
\text { group }(n=38)\end{array}$ & $\begin{array}{l}\text { Conventional } \\
\text { group }(n=\mathbf{3 8})\end{array}$ & $P$ value \\
\hline \multicolumn{4}{|c|}{ VAS pain outcomes } \\
\hline $\begin{array}{l}\text { Pain score after } \\
24 \text { hours }\end{array}$ & $2.6 \pm 0.2$ & $3.4 \pm 0.6$ & $<0.000 \mathrm{I}$ \\
\hline $\begin{array}{l}\text { Pain score after } \\
48 \text { hours }\end{array}$ & $1.7 \pm 0.1$ & $1.8 \pm 0.4$ & 0.14 \\
\hline \multicolumn{4}{|c|}{ Dose of analgesic consumption postoperatively (diclofenac) } \\
\hline Mean \pm SD (mg) & $40 \pm 7.3$ & $66 \pm 12$ & $<0.0001$ \\
\hline \multicolumn{4}{|c|}{ Satisfaction with cosmetic results 3 months postoperatively } \\
\hline Mean \pm SD & $9.1 \pm 0.5$ & $4.9 \pm 0.6$ & $<0.0001$ \\
\hline \multicolumn{4}{|c|}{ Incision length (cm) } \\
\hline Mean \pm SD & $3.2 \pm 0.9$ & $5.4 \pm 0.7$ & $<0.0001$ \\
\hline
\end{tabular}

Abbreviations: MIVAT, minimally invasive video-assisted thyroidectomy; VAS, visual analogue score. 
applicable to small symptomatic nodules, toxic nodules, and follicular lesions, requiring further histological assessment.

The advantages of minimally invasive thyroidectomy have been demonstrated by other groups. As in this study, the major benefits center on reductions in pain and improvements in cosmetic results. ${ }^{13,15,45,52-56}$ The majority of these studies have evaluated the MIVAT technique.

The operative time for MIVAT remains greater than that of conventional surgery, a finding which is common to a number of studies of minimally invasive approaches to the thyroid. ${ }^{23,42,45}$ With greater experience, it is likely that operative times for MIVAT will decrease, particularly with the refinement of electrothermal vessel sealing devices, which have now become the preferred method for vessel control and dissection in open and minimally invasive thyroidectomy. This technology, in addition to the fact that MIVAT minimizes the amount of unnecessary dissection required to expose the thyroid, will likely result in the decrease in operative times in future. We hypothesize that the smaller skin incision and decreased area of dissection associated with MIVAT results in less disruption of the cutaneous nerve supply, meaning less postoperative pain. To avoid the potential problem of information bias influencing the reporting of pain and cosmetic scores, we blinded patients preoperatively. Postoperatively, there is the potential for bias in reporting of pain scores from the MIVAT group; however, the combined reduction after day 1 pain scores and analgesic requirement suggests that the improvement effect is real. Similar benefits in terms of pain reduction have been reported in other series. ${ }^{45,48,52,55}$

In conclusion, MIVAT is a safe procedure that produces outcomes; in view of short-term adverse events, similar to those of open thyroidectomy, the procedure needs a longer operative time and is superior in terms of immediate postoperative pain and cosmetic results.

\section{Disclosure}

The author reports no conflicts of interest.

\section{References}

1. Miccoli P, Pinchera A, Cecchini G, et al. Minimally invasive videoassisted parathyroid surgery for primary hyperparathyroidism. J Endocrinol Invest. 1997;20:429-430.

2. Ohgami M, Ishii S, Arisawa Y, et al. Scarless endoscopic thyroidectomy: breast approach for better cosmesis. Surg Laparosc Endosc Percutan Tech. 2000;10:1-4.

3. Miccoli P, Bendinelli C, Vignali E, et al. Endoscopic parathyroidectomy: report of an initial experience. Surgery. 1998;124:1077-1079.

4. Sgourakis G, Sotiropoulos GC, Neuhäuser M. Comparison between minimally invasive video-assisted thyroidectomy and conventional thyroidectomy: is there any evidence-based information? Thyroid. 2008; 18:721-727.
5. Del Rio P, Lucia Sommaruga, Pisani P, Palladino S, Francesca M. Minimally invasive video-assisted thyroidectomy in differentiated thyroid cancer: a 1-year follow-up. Surg Laparosc Endosc Percutan Tech. 2009;19:290-292.

6. Henry F, Defechereux T, Gramatica L. Endoscopic parathyroidectomy via a lateral neck incision. Ann Chir. 1999;53:302-306.

7. Gagner M. Endoscopic subtotal parathyroidectomy in patients with primary hyperparathyroidism. Br J Surg. 1996;83:875.

8. Naitoh T, Gagner M, Garcia-Ruiz A. Endoscopic endocrine surgery in the neck: an initial report of endoscopic subtotal parathyroidectomy. Surg Endosc. 1998;12:202-206.

9. Gottlieb A, Sprung J, Zheng XM, Gagner M. Massive subcutaneous emphysema and severe hypercapnia in a patient during endoscopic transcervical parathyroidectomy using carbon dioxide insufflation. Anesth Analg. 1997;84:1154-1156.

10. Shimizu K, Akira S, Jasmi Y, et al. Video-assisted neck surgery: endoscopic resection of thyroid tumors with a very minimal neck wound. J Am Coll Surg. 1999;188:697-703.

11. Bellantone R, Lombardi P, Raffaelli M, Rubino F, Boscherini M, Perilli W. Minimally invasive, totally gasless video-assisted thyroid lobectomy. Am J Surg. 1999; 177:342-343.

12. Miccoli P, Berti P, Conte M, Bendinelli C, Marcocci C. Minimally invasive surgery for thyroid small nodules: preliminary report. J Endocrinol Invest. 1999;22:849-851.

13. Miccoli P, Berti P, Raffaelli M, Materazzi G, Baldacci S, Rossi G. Comparison between minimally invasive video-assisted thyroidectomy and conventional thyroidectomy: a prospective randomized study. Surgery. 2001;130:1039-1043.

14. Miccoli P, Berti P, Materazzi G, Minuto M, Barellini L. Minimally invasive video-assisted thyroidectomy: five years of experience. J Am Coll Surg. 2004;199:243-248.

15. Bellantone R, Lombardi CP, Bossola M, et al. Video-assisted vs conventional thyroid lobectomy: a randomized trial. Arch Surg. 2002;137:301-304.

16. Palazzo F, Sebag F, Henry F. Endocrine surgical technique: endoscopic thyroidectomy via the lateral approach. Surg Endosc. 2006;20:339-342.

17. Ikeda Y, Takami H, Niimi M, Kan S, SasakiY, Takayama J. Endoscopic thyroidectomy by the axillary approach. Surg Endosc. 2001;15:1362-1364.

18. Terris J, Chin E. Clinical implementation of endoscopic thyroidectomy in selected patients. Laryngoscope. 2006;116:1745-1748.

19. Ujiki B, Sturgeon C, Denham D, Yip L, Angelos P. Minimally invasive video-assisted thyroidectomy for follicular neoplasm: is there an advantage over conventional thyroidectomy? Ann Surg Oncol. 2006;13: $182-186$.

20. Terris J, Angelos P, Steward L, Simental A. Minimally invasive videoassisted thyroidectomy. Arch Otolaryngol Head Neck Surg. 2008;134: 81-84.

21. Shimizu K. Minimally invasive thyroid surgery. Best Pract Res Clin Endocr Metab. 2001;15:123-137.

22. Shimizu K, Akira S, Tanaka S. Video assisted neck surgery: endoscopic resection of benign thyroid tumor aiming at scarless surgery on the neck. J Surg Oncol. 1998;69:178-180.

23. Ikeda Y, Takami H, Sasaki Y, Takayama J, Niimi M, Kan S. Comparative study of thyroidectomies. Endoscopic surgery vs conventional open surgery. Surg Endosc. 2002;16:1741-1745.

24. Ikeda Y, Takami H, Tajima G, et al. Direct mini-incision thyroidectomy. Biomed Pharmacother. 2002;56:60-63.

25. Ikeda Y, Takami H, Tajima G, et al. Total endoscopic thyroidectomy: axillary or anterior chest approach. Biomed Pharmacother. 2002;56:72-78.

26. Ikeda Y, Takami H, Sasaki Y, Takayama J, Kurihara H. Are there significant benefits of minimally invasive endoscopic thyroidectomy? World $J$ Surg. 2004;28:1075-1078.

27. Miccoli P. Minimally invasive surgery for thyroid and parathyroid diseases. Surg Endosc. 2002;16:3-6.

28. Miccoli P, Bellantone R, Mourad M, Walz M, Raffaeli M, Berti P. Minimally invasive video-assisted thyroidectomy: multi-istitutional experience. World J Surg. 2002;26:972-975. 
29. Miccoli P, Berti P, Raffaeli M, Conte M, Materazzi G, Galleri D. Minimally invasive video-assisted thyroidectomy. Am J Surg. 2001;181:567-570.

30. Miccoli P, Berti P, Raffaeli M, Materazzi G, Conte M, Galleri D. Impact of Harmonic Scalpel on operative time durino video-assisted thyroidectomy. Surg Endosc. 2002;16:663-666.

31. Miccoli P, Elisei R, Materazzi G, et al. Minimally invasive videoassisted thyroidectomy for papillary carcinoma: a prospective study of its completeness. Surgery. 2002;132:1070-1074.

32. Berti P, Materazzi G, Conte M, Galleri D, Miccoli P. Visualization of the external branch of the superior laryngeal nerve during video-assisted thyroidectomy. J Am Coll Surg. 2002;194: 573-574.

33. Mourad M, Pugin F, Elias B, et al. Contributions of the video-assisted approach to thyroid and parathyroid surgery. Acta Chir Belg. 2002; 102:323-327.

34. Musella M, Lombardi S, Caiazzo P, et al. La chirurgia video-assistita della tiroide: note di tecnica e analisi dei risultati. Ann Ital Chir. 2003;1:3-5.

35. Bellantone R, Lombardi C, Raffaeli M, et al. Video-assisted thyroidectomy for papillary thyroid carcinoma. Surg Endosc. 2003;17:1604-1608.

36. Bellantone R, Lombardi C, Raffaeli M, Boscherini M, De Crea C, Traini E. Video-assisted thyroidectomy. J Am Coll Surg. 2002;194:610-614.

37. Lombardi C, Raffaeli M, Modesti C, Boscherini M, Bellantone R. Video-assisted thyroidectomy under local anesthesia. Am J Surg. 2004; 187:515-518.

38. Ruggieri M, Straniero A, Pacini F, Mariuolo A, Mascaro A, Genderini M. Video-assisted surgery of the thyroid diseases. Eur Rev Med Pharmacol Sci. 2003;7:91-96.

39. Ruggieri M, Straniero A, Pacini F, Mariuolo A, Mascaro A, Genderini M. Comparison between video-assisted thyroidectomy and conventional thyroidectomy. Preliminary aspects. Policlinico J Surg. 2003;110:11-17.

40. Ruggieri M, Straniero A, Genderini M, et al. The minimally invasive open video-assisted approach in surgical thyroid diseases. BMC Surg. 2005;5:9.

41. Miccoli P, Minuto N, Ugolini C, Pisano R, Fosso A, Berti P. Minimally invasive video-assisted thyroidectomy for benign thyroid disease: an evidence-based review. World J Surg. 2008;32:1333-1340.

42. Hegazy A, Khater A, Setit E, Amin A, Kotb Z, El Shafei A, et al. Minimally invasive video-assisted thyroidectomy for small follicular thyroid nodules. World J Surg. 2007;31:1743-1750.
43. Gal I, Solymosi T, Szabo Z, Balint A, Bolgar G. Minimally invasive video-assisted thyroidectomy and conventional thyroidectomy: a prospective randomized study. Surg Endosc. 2008;22:2445-2449.

44. Alvarado R, McMullen T, Sidhu B, Delbridge W, Sywak S. Minimally invasive thyroid surgery for single nodules: an evidence-based review of the lateral mini-incision technique. World J Surg. 2008;32:1341-1348.

45. Sgourakis G, Sotiropoulos C, Neuhäuser M, Musholt J, Karaliotas C, Lang H. Comparison between minimally invasive video-assisted thyroidectomy and conventional thyroidectomy: is there any evidence-based information? Thyroid. 2008;18:721-727.

46. Duh QY. Presidential address: minimally invasive endocrine surgery standard of treatment or hype? Surgery. 2003;134:849-857.

47. Gagner M, Inabnet B. Endoscopic thyroidectomy for solitary thyroid nodules, Thyroid. 2001;11:161-163.

48. Sywak S, Yeh W, McMullen T, et al. A randomized controlled trial of minimally invasive thyroidectomy using the lateral direct approach versus conventional hemi-thyroidectomy. Surgery. 2008;144:1016-1022.

49. Lennquist S, Thyroidectomy. In: Clark OH. Duh QY. eds. Textbook of Endocrine Surgery. Philadelphia, PA: WB. Saunders \& Company; 1997:147-153.

50. John L, Frank K, Chris M. Visual analogue scale (VAS): a method of scoring pain. Br J Aneth. 2002;80:154-158.

51. Bayat A, McGrouther A, Ferguson J. Skin scarring. BMJ. 2003;326:88-92.

52. Cavicchi O, Piccin O, Ceroni R, Caliceti U. Minimally invasive nonendoscopic thyroidectomy. Otolaryngol Head Neck Surg. 2006;135: 744-747.

53. Lombardi P, Raffaelli M, Princi P, De Crea C, Bellantone R. Video-assisted thyroidectomy: report of a 7-year experience in Rome. Langenbecks Arch Surg. 2006;391:174-177.

54. Terris J, Haus M, Nettar K, Ciecko S, Gourin G. Prospective evaluation of endoscopic approaches to the thyroid compartment. Laryngoscope 2004;114: 1377-1382.

55. Terris J, Bonnett A, Gourin G, Chin E. Minimally invasive thyroidectomy using the Sofferman technique. Laryngoscope. 2005;115:1104-1108.

56. Del Rio P, Berti M, Sommaruga L, Arcuri F, Cataldo S, Sianesi M. Pain after minimally invasive video assisted and after minimally invasive open thyroidectomy-results of a prospective outcome study. Langenbecks Arch Surg. 2008;393:271-273.
Open Access Surgery

\section{Publish your work in this journal}

Open Access Surgery is an international, peer-reviewed, open access journal that focuses on all aspects of surgical procedures and interventions. Patient care around the peri-operative period and patient outcomes post surgery are key topics. All grades of surgery from minor cosmetic interventions to major surgical procedures are covered. Novel techniques

\section{Dovepress}

and the utilization of new instruments and materials, including implants and prostheses that optimize outcomes constitute major areas of interest. The manuscript management system is completely online and includes a very quick and fair peer-review system. Visit http://www.dovepress.com/ testimonials.php to read real quotes from published authors. 